\title{
Is Bacille Calmette-Gu é rin (BCG) Vaccine a Known Risk Factor for Latent Tuberculosis Infection?: A Cross-sectional Study on 180 New Immigrants from BCG-vaccinated Countries to Kuwait
}

\author{
Adel AL-Harbie ${ }^{1 *}$, Kim Picozzi ${ }^{1}$, Michael Thrusfield ${ }^{2}$, Ali Sadek ${ }^{3}$ and Susan C Welburn ${ }^{1}$ \\ ${ }^{1}$ Division of Pathway Medicine \& Centre for Infectious Diseases, School of Biomedical Sciences, College of Medicine \& Veterinary Medicine, The University of Edinburgh, \\ Chancellor's Building, 49 Little France Crescent, Edinburgh, EH16 4SB, UK \\ ${ }^{2}$ Veterinary Clinical Sciences, Royal (Dick) School of Veterinary Studies. The University of Edinburgh, Easter Bush, EH25 9RG, UK \\ ${ }^{3}$ Department of Public Health and Community Medicine, Faculty of Medicine, University of Alexandria, Egypt
}

\begin{abstract}
The Bacelle Calmette-Guérin (BCG) vaccine has existed for 90 years and is the most widely used of all current national childhood immunization programmes. The impact of BCG vaccination on transmission of Mycobacterium tuberculosis is not clear or whether BCG confers lifelong immunity through sufficient protection against formation and diagnosis of latent tuberculosis infection (LTBI) is recently questionable especially in tuberculosis endemic regions and vaccinated high risk individuals, which was discussed along the paper work following a new evidencebased criteria for LTBI diagnosis.
\end{abstract}

Keywords: Bacelle Calmette Guerin (BCG); Tuberculosis (TB); Latent tuberculosis infection (LTBI); Tuberculin skin test (TST)

\section{Introduction}

Since the 20th century the Bacille Calmette-Guérin (BCG) vaccine there is only one defensive tool against Mycobacterium tuberculosis (MTB) introduced as a shot of a 90-year-old vaccine (attenuated virulence of Mycobacterium bovis). BCG limits the growth and protect against MTB and aids in clearance of bacillary loads during chemotherapeutic treatment in the active post-infective stage [1]. BCG vaccination can have obvious public health advantages. It can lessen the burden of TB-related disorders such as LTBI prevalence and active TB incidence in children [2]. TB incidence rose again after abandoning routine BCG in the mid-1980s even with the introduction of other preventive measures [3]. But the efficacy impacts of BCG vaccination whether confers lifelong immunity or adversely causing tuberculosis (TB) through indirectly forming latent tuberculosis infection (LTBI) is still unclear. Worldwide the tuberculin skin test (TST) has been the standard diagnostic test for detection of LTBI for more than 100 years. It was first described by Robert Koch in 1890, and involves injecting intradermally a purified protein derivative (PPD) of $0.1 \mathrm{ml}$ tuberculin (which is a glycerol extract of the bacillus) followed by measurement of the localized delayed-type hypersensitivity (DTH-IV) reaction [4]. The TST has several limitations and cannot distinguish between previous BCG vaccination and current TB infection due to poor specificity in BCG negative people and poor sensitivity in BCGvaccinated individuals. Meta-analysis has shown that previous BCG administration increases the likelihood of TST false-positive results up to 15 years after-vaccination [5].

BCG vaccination might alter the interpretation of a positive PPD, and therefore TST interpretation is extremely limited as a diagnostic tool to prove whether a positive result is caused by MTB infection or crossreactivity resulting from BCG vaccination (containing live attenuated $M$. bovis antigens), and has to be interpreted taking into consideration both the pre-test risk of TB infection and BCG vaccination status.

\section{Objective}

To assess the interference effect of BCG vaccination on the results of the tuberculin skin test.

\section{Sub-objective}

Assess with evidence-based the cross-reactive effects of BCG vaccine on Mantoux test (used for LTBI diagnosis) according to a new defined categories of latent TB infection using four TB diagnostic testing implemented on healthy new immigrants.

\section{Materials and Methods}

The study design was a cross-sectional study involving a sample of 180 new immigrants to Kuwait during four months (between February and May) 2010 during their compulsory registration at $\mathrm{Al}$ Farwaniya Immigration Centre (the most populous region in Kuwait covering 907,321 out of the $3,442,945$ total residential population). Included participants were randomly chosen as one in every thirty four expatriates without selection bias.

The study screening tools were a structured questionnaire to assess the socio-economic characteristics and past history of BCG vaccination with careful examination for the presence of characteristic BCG scar on both arms. Four tests were performed on each immigrant simultaneously. Two blood samples for both IGRAs (three $1 \mathrm{ml}$ tubes for QuantiFERON Gold In-Tube and one $8 \mathrm{ml}$ tube for T-SPOT.TB test) were taken. Thirdly, this was followed by performing TST through intradermal administration of five tuberculin units (5TU) of $0.1 \mathrm{ml}$ of purified protein derivative (PPD) (Tubersol: Sanofi Pasteur Ltd, Toronto, Ontario, Canada), using $1 \mathrm{ml}$ disposable tuberculin syringes,

${ }^{*}$ Corresponding author: Adel AL-Harbie, Division of Pathway Medicine \& Centre for Infectious Diseases, School of Biomedical Sciences, College of Medicine \& Veterinary Medicine, The University of Edinburgh, Chancellor's Building, 49 Little France Crescent, Edinburgh, EH16 4SB, UK, E-mail: Sadelharbie668@yahoo.com

Received August 22, 2012; Accepted September 27, 2012; Published October 03, 2012

Citation: Harbie AA, Picozzi K, Thrusfield M, Sadek A, Welburn SC (2012) Is Bacille Calmette-Guérin (BCG) Vaccine a Known Risk Factor for Latent Tuberculosis Infection?: A Cross-sectional Study on 180 New Immigrants from BCG-vaccinated Countries to Kuwait. J Vaccines Vaccin 3:150. doi:10.4172/2157-7560.1000151

Copyright: @ 2012 Harbie AA, et al. This is an open-access article distributed under the terms of the Creative Commons Attribution License, which permits unrestricted use, distribution, and reproduction in any medium, provided the original author and source are credited. 
Citation: Harbie AA, Picozzi K, Thrusfield M, Sadek A, Welburn SC (2012) Is Bacille Calmette-Guérin (BCG) Vaccine a Known Risk Factor for Latent Tuberculosis Infection?: A Cross-sectional Study on 180 New Immigrants from BCG-vaccinated Countries to Kuwait. J Vaccines Vaccin 3:150. doi:10.4172/2157-7560.1000151

Page 2 of 5

\begin{tabular}{|l|l|l|l|l|l|}
\hline \multicolumn{7}{|l|}{ Tuberculosis diagnostic test results } & & \multicolumn{2}{l|}{ LTBI case } \\
\hline Old (Standard) & New & & Test score & definition \\
\hline CXR & TST & QFT-GIT & T-SPOT .TB & & \\
\hline- & & & & & \\
\hline+ & - & - & - & 1 & Negligible \\
\hline- & - & - & - & 2 & Low \\
\hline- & + & - & - & 3 & Low \\
\hline- & - & + & - & 4 & Low \\
\hline+ & - & - & + & 5 & Low \\
\hline+ & + & - & - & 6 & Average \\
\hline- & - & + & - & 7 & High \\
\hline+ & + & + & - & 8 & High \\
\hline & - & - & + & 9 & High \\
\hline- & & & & & \\
\hline- & + & - & + & 10 & High \\
\hline+ & - & + & + & 11 & Extremely High \\
\hline- & - & + & + & 12 & Extremely High \\
\hline+ & + & + & + & 13 & Extremely High \\
\hline
\end{tabular}

CXR=chest $X$-ray, TST=tuberculin skin test, IGRAs=interferon gamma release assays, QFT-GIT=QuantiFERON Gold In-Tube test, T-SPOT .TB=T-SPOT .TB test, LTBI=latent tuberculosis infection

*Risk defined according to Thrusfield, M. (2007): Negligible (of likelihood) $=$ Insignificant, Low=less than average, Average=usual amount of risk, High=above the normal or average level, Extremely high=outermost higher than average

Table 1: New classification representing categorization criteria for diagnosis of latent tuberculosis infection cases using a combination of four-tuberculosis diagnostic tests and score for latent tuberculosis infection case diagnosis

\begin{tabular}{|c|c|c|c|c|c|}
\hline \multicolumn{2}{|c|}{ Mantoux } & Score grade & LTBI diagnosis & Final result & n (\%) \\
\hline \multicolumn{6}{|c|}{ response $(\mathrm{mm})$} \\
\hline 0 & & I & Negative(no reaction) & Normal & $170(96.04 \%)$ \\
\hline 1 & $-<5$ & II & Normal (reactive) & Normal & $6(3.38 \%)$ \\
\hline 5 & $-<10$ & III & Borderline & Normal & $1(0.05 \%)$ \\
\hline \multicolumn{2}{|c|}{$10-<15$} & IV & Positive & Abnormal & $0(0.00 \%)$ \\
\hline \multicolumn{2}{|c|}{$15-<20$} & V & Highly positive & Abnormal & $0(0.00 \%)$ \\
\hline \multicolumn{2}{|c|}{$>20$} & VI & Definite & Abnormal & $0(0.00 \%)$ \\
\hline \multicolumn{2}{|c|}{ Excluded } & - & Cannot be judged & - & $3(1.66 \%)$ \\
\hline
\end{tabular}

Modified 'cut-off' point value of TST induration was more than $10 \mathrm{~mm}$, score (-)=no score for excluded case (due to missed follow-up or result reading after 5days), $\mathrm{mm}=$ millimetre induration

Table 2: Skin test response and score frequency of latent tuberculosis infection of the 180 new immigrants to Kuwait, February-May, 2010.

on the volar surface of the mid-anterior left forearm. The TST result was read as firm and well circumscribed indurations or soft ill-defined swelling/margins using a small flexible caliper (a 10-15 cm length ruler calibrated in $\mathrm{mm}$ ). Adverse skin reactions such as erythematous skin reactions or hematomas or vesicles were also investigated. A TST reaction of transverse diameters of the palpable hardened skin areas more than or equal $10 \mathrm{~mm}(>10 \mathrm{~mm})$ was considered positive, in accordance with The American Thoracic Society and Centers for Disease Control and Prevention guidelines and Ministry of Health in Kuwait [6]. Fourthly, a chest X-ray was performed. All healthy adults aged between 18 and 60 years were randomly enrolled and TST reaction results interpreted within 48 hours and 72 hours. Immigrants with a history of previous TST less than six months prior to enrollment and/ or at increased risk of adverse reactions(s) to TST such as venipuncture or skin allergy and/or having acute infectious disease within the last six months were excluded. Participants came after 5 days and/or missed follow-up results were also excluded.

Table 1 presents a new laboratory classification of diagnostic testing, which can be considered as new criteria for LTBI case definition.

\section{Statistical analysis}

Lowest accepted sample size calculated by the Confidence Interval Analysis Software was 167 out of average annual 80,000 expatriates (theoretically are healthy or free-of-disease) entering to Kuwait [7] Data were analyzed using the Statistical Package for Social Sciences software, version 17.0 [8]. Categorical variables were analyzed using a Likelihood ratio (LLR $\chi 2$ (d.f.)) test when Pearson's chi square was inappropriate for small sample (measured by SPSS as expected values were more than $20 \%$ or more 5 categories of total table categories). Similar to LLR $\chi 2$ use, non-normally distributed continuous variables (age of BCG vaccination in years) were analyzed using a KruskalWallis (KW $\chi 2$ (d.f.) test and a p-value of less than 0.05 was considered as the level of statistical significance. Data limits using the mid-spread (middle 50\%) represented by the interquartile range (IQR) and semi-interquartile range (SIQR) as half the interquartile range [9]. Questionnaire quantitative variables were drawn as box-and-whiskers plots diagrams using SPSS version 17.0 [8].

\section{Results}

\section{Socio-demographic characteristics}

The overall median age of the immigrants was 31.5 years, with an interquartile range (IQR) of 11 years and the semi-interquartile range $(\mathrm{SIQR})$ of 5.5 year $(\mathrm{KW} \chi 2(4)=25.741, p<0.001)$. Statistically significant differences were detected between nationality and LTBI case categories. Most of the immigrants in this study $77.22 \%(139 / 180)$ came from counties in which TB was endemic: Indians 35\%, Filipinos $19.44 \%$, Nepalis 15\%, Ethiopians $7.78 \%$ and Sri Lankans 3.3\%. Egyptians represented the majority of immigrants coming from non-endemic countries: $14.44 \%(26 / 180)(\operatorname{LLR} \chi 2(52)=72.522, p=0.032)$

\section{Tuberculin skin test}

Mantoux (induration) reaction was measured in 98.33\% (177/180) who fulfilled the inclusion criteria for TST results. The TST results of three excluded immigrants were as follows: two participants came on day 7 (a male Indian electrician and a female Nepali housemaid) and one participant did not return for a TST reading (a female Ethiopian housemaid). The frequency of LTBI reactions in the new immigrants, including the three missed follow-up participants, is shown in Table 2.

According to the induration reaction, the prevalence of LTBI in the sample of new immigrants was zero $(0 / 177)$ using the TST method. Applying the new classification criteria of LTBI, all participants belonged to the normal results within score I (zero=negative reaction) and score II ( $\leq 5 \mathrm{~mm}$ induration) in $97.78 \%$ (176/180). Immigrants had score III (= $5-<10 \mathrm{~mm}$ induration) were $0.56 \%(1 / 180)$ with no observed case for positive abnormal reaction above the modified 'cutoff' value $(>10 \mathrm{~mm})(\operatorname{LLR} \chi 2(8)=33.865, p<0.001)$ as shown in the next Table 3.

Average LTBI category is zero (means no detected cases), Missed=excluded case due to missed follow-up or came after 5 days for reading of TST reaction, cannot be judged means excluded cases (3 missed follow-up for TST results and one pregnant female not preformed chest X-ray due to contraindication)

\section{BCG vaccination status}

Analysis of the influence of BCG vaccination status on test results 
Citation: Harbie AA, Picozzi K, Thrusfield M, Sadek A, Welburn SC (2012) Is Bacille Calmette-Guérin (BCG) Vaccine a Known Risk Factor for Latent Tuberculosis Infection?: A Cross-sectional Study on 180 New Immigrants from BCG-vaccinated Countries to Kuwait. J Vaccines Vaccin 3:150. doi:10.4172/2157-7560.1000151

Page 3 of 5

\begin{tabular}{|c|c|c|c|c|c|c|c|c|c|c|c|c|c|c|c|c|c|c|}
\hline & & & \multicolumn{2}{|c|}{ Negligible } & \multirow{2}{*}{$\begin{array}{l}\text { Low } \\
(n=36)\end{array}$} & & \multirow{2}{*}{$\begin{array}{l}\text { Average } \\
(n=0)\end{array}$} & & \multirow{2}{*}{$\begin{array}{l}\text { High } \\
(n=4)\end{array}$} & & \multicolumn{2}{|c|}{ Extremely High } & \multicolumn{2}{|c|}{$\begin{array}{l}\text { Can } \\
\text { not be judged }\end{array}$} & \multirow{2}{*}{\begin{tabular}{|l|} 
Total \\
$(n=180)$
\end{tabular}} & \multirow{2}{*}{\multicolumn{2}{|c|}{ Likelihood }} & \multirow[b]{2}{*}{$p$-value } \\
\hline \multicolumn{2}{|c|}{ Tuberculin Skin Test } & & $(n=90)$ & & & & & & & & $(n=46)$ & & & & & & & \\
\hline & & & $n$ & $\%$ & $n$ & $\%$ & $n$ & $\%$ & $n$ & $\%$ & $\mathrm{n}$ & $\%$ & $n$ & $\%$ & $n$ & $\%$ & & \\
\hline & \multicolumn{2}{|c|}{ Score I $(<5)$} & 90 & 100.00 & 36 & 100.00 & 0 & 0.00 & 3 & 75.00 & 46 & 100.00 & 1 & 25.00 & 176 & 97.78 & & \\
\hline \multirow[t]{4}{*}{ TST Score } & \multicolumn{2}{|c|}{ Score II (5-9) } & 0 & 0.00 & 0 & 0.00 & 0 & 0.00 & 1 & 25.00 & 0 & 0.00 & 0 & 0.00 & 1 & 0.56 & $\begin{array}{l}L \quad L \quad R \\
X^{2}(8)=\end{array}$ & $<0.001$ \\
\hline & \multicolumn{2}{|c|}{ Missed } & 0 & 0.00 & 0 & 0.00 & 0 & 0.00 & 0 & 0.00 & 0 & 0.00 & 3 & 75.00 & 3 & 1.67 & 33.865 & \\
\hline & 0 & (Negative- & & & & & & & & & & & & & & & & \\
\hline & \multicolumn{2}{|c|}{ No reaction) } & 85 & 94.44 & 36 & 100.00 & 0 & 0.00 & 3 & 75.00 & 45 & 97.83 & 1 & 25.00 & 170 & 94.44 & & \\
\hline TST & $<5$ & (Reactive- & \multirow{2}{*}{5} & \multirow[b]{2}{*}{5.56} & \multirow[b]{2}{*}{0} & \multirow[b]{2}{*}{0.00} & \multirow[b]{2}{*}{0} & \multirow[b]{2}{*}{0.00} & \multirow[b]{2}{*}{0} & \multirow[b]{2}{*}{0.00} & \multirow[b]{2}{*}{1} & \multirow[b]{2}{*}{2.17} & \multirow[b]{2}{*}{0} & \multirow[b]{2}{*}{0.00} & \multirow[b]{2}{*}{6} & \multirow[b]{2}{*}{3.33} & 2 & \\
\hline & \multirow{2}{*}{\multicolumn{2}{|c|}{ Normal) }} & & & & & & & & & & & & & & & & \\
\hline cutaneous in & & & & & & & & & & & & & & & & & & \\
\hline duration size & & & & & & & & & & & & & & & & & 37.947 & $<0.001$ \\
\hline \multirow[t]{3}{*}{$(\mathrm{mm})$} & $5-9$ & (Reactive- & & & & & & & & & & & & & & & & \\
\hline & Bord & erline) & 0 & 0.00 & 0 & 0.00 & 0 & 0.00 & 1 & 25.00 & 0 & 0.00 & 0 & 0.00 & 1 & 0.56 & & \\
\hline & Miss & & 0 & 0.00 & 0 & 0.00 & 0 & 0.00 & 0 & 0.00 & 0 & 0.00 & 3 & 75.00 & 3 & 1.67 & & \\
\hline $\begin{array}{l}\text { TST adverse } \\
\text { reaction }\end{array}$ & No & & 90 & 100.00 & 36 & 100.00 & 0 & 0.00 & 4 & 100.00 & 46 & 100.00 & 1 & 25.00 & 177 & 98.33 & $\begin{array}{l}L \quad L \quad R \\
X^{2}(4)=\end{array}$ & $<0.001$ \\
\hline & Miss & & 0 & 0.00 & 0 & 0.00 & 0 & 0.00 & 0 & 0.00 & 0 & 0.00 & 3 & 75.00 & 3 & 1.67 & 26.017 & \\
\hline
\end{tabular}

Average LTBI category is zero (means no detected cases), Missed=excluded case due to missed follow-up or came after 5 days for reading of TST reaction, cannot be judged means excluded cases ( 3 missed follow-up for TST results and one pregnant female not preformed chest X-ray due to contraindication)

Table 3: Distribution of tuberculin skin test results according to latent tuberculosis infection categories of 180 new immigrants to Kuwait, February-May, 2010.

\begin{tabular}{|c|c|c|c|c|c|c|c|c|c|c|c|c|c|c|c|c|c|c|}
\hline & & \multicolumn{2}{|c|}{ Negligible } & Low & & \multicolumn{2}{|c|}{ Average } & High & & \multicolumn{2}{|c|}{ Extremely High } & \multicolumn{2}{|c|}{$\begin{array}{l}\text { Can } \\
\text { not be judged }\end{array}$} & \multirow{2}{*}{\multicolumn{2}{|c|}{ Total }} & & & \multirow[b]{3}{*}{$\mathrm{p}$-value } \\
\hline $\begin{array}{l}\text { BCG } \\
\text { against }\end{array}$ & vaccination & & & & & & & & & & & & & & & \multicolumn{2}{|c|}{ Likelihood } & \\
\hline \multirow[t]{2}{*}{ TB } & & $(n=90)$ & & $(n=36)$ & & $(n=0)$ & & $(n=4)$ & & $(n=46)$ & & $(n=4)$ & & $(n=180)$ & & ratio & & \\
\hline & & $n$ & $\%$ & $n$ & $\%$ & $n$ & $\%$ & $n$ & $\%$ & $n$ & $\%$ & $n$ & $\%$ & $n$ & $\%$ & & & \\
\hline \multirow{3}{*}{$\begin{array}{l}\text { History of } \\
\text { vaccination }\end{array}$} & Yes & 78 & 87 & 28 & 77.78 & 0 & 0 & 4 & 100.00 & 41 & 89 & 3 & 75.00 & 154 & 85.56 & & & \\
\hline & No & 10 & 11 & 7 & 19.44 & 0 & 0 & 0 & 0.00 & 5 & 11 & 1 & 25.00 & 23 & 12.78 & $\begin{array}{l}\mathrm{L} L \mathrm{~L} R \\
\mathrm{X}^{2}=\end{array}$ & & 0.706 \\
\hline & Unknown & 2 & 2 & 1 & 2.78 & 0 & 0 & 0 & 0.00 & 0 & 0 & 0 & 0.00 & 3 & 1.67 & 5.470 & & \\
\hline \multirow{2}{*}{$\begin{array}{l}\text { Age } \\
B \quad C \quad G \\
\text { vaccination }\end{array}$} & Median & \multirow[b]{2}{*}{5.00} & \multirow[b]{2}{*}{ (2) } & \multirow[b]{2}{*}{6.00} & \multirow[b]{2}{*}{ (3) } & \multirow[b]{2}{*}{-} & \multirow[b]{2}{*}{-} & \multirow[b]{2}{*}{7.50} & \multirow[b]{2}{*}{ (6) } & \multirow[b]{2}{*}{5.00} & \multirow[b]{2}{*}{ (2) } & \multirow[b]{2}{*}{4.00} & \multirow[b]{2}{*}{$(-)$} & \multirow[b]{2}{*}{5} & \multirow[b]{2}{*}{ (2) } & $\mathrm{KW}$ & $X_{(4)}^{2}=$ & \\
\hline & & & & & & & & & & & & & & & & \multirow[b]{2}{*}{3.330} & & 0.504 \\
\hline (years) & (IQR) & & & & & & & & & & & & & & & & & \\
\hline \multirow{2}{*}{$\begin{array}{l}\text { Presence of } \\
\text { BCG scar }\end{array}$} & f Positive & 79 & 87.78 & 27 & 75.00 & 0 & 0 & 4 & 100.00 & 41 & 89.13 & 4 & 100.00 & 155 & 86.11 & $\begin{array}{l}\mathrm{L} L \mathrm{~L} R \\
\mathrm{X} 2_{(4)}=\end{array}$ & & 0.192 \\
\hline & Negative & 11 & 12.22 & 9 & 25.00 & 0 & 0 & 0 & 0.00 & 5 & 10.87 & 0 & 0.00 & 25 & 13.89 & 6.104 & & \\
\hline Animal & Yes & 51 & 56.67 & 18 & 50 & 0 & 0 & 1 & 25.00 & 24 & 52.17 & 0 & 0.00 & 94 & 52.22 & $\begin{array}{l}\mathrm{L} L \mathrm{~L} R \\
\mathrm{X}^{2}=\end{array}$ & & 0.094 \\
\hline $\begin{array}{l}\text { exposure in } \\
\text { country }\end{array}$ & No & 39 & 43.33 & 18 & 50 & 0 & 0 & 3 & 75.00 & 22 & 47.83 & 4 & 100.00 & 86 & 47.78 & & & \\
\hline & Yes & 16 & 17.78 & 5 & 14 & 0 & 0 & 0 & 0.00 & 7 & 15.22 & 0 & 0.00 & 28 & 15.56 & LLR $X^{2}$ & & \\
\hline cow? & No & 74 & 82.22 & 31 & 86 & 0 & 0 & 4 & 100.00 & 39 & 84.78 & 4 & 100.00 & 152 & 84.44 & 3.114 & & \\
\hline
\end{tabular}

Table 4: Distribution of Bacillus Calmette-Guérin (BCG) vaccination status against tuberculosis according to latent tuberculosis infection categories of 180 new immigrants to Kuwait, February-May, 2010.

is shown in Table 3. BCG vaccination status was ascertained from the participants through availability of reliable past history of vaccination and/or presence of a characteristic BCG scar. Analysis of the effects of BCG vaccination status (either vaccinated or non-vaccinated) represented in relation to the defined cases of latent tuberculosis infection categories is shown in Table 4 .

The overall median age of BCG vaccination for the 180 participants was 5 years (IQR=2 years). The 'high' LTBI group had been vaccinated at older ages (median $=7.5$ years, $\mathrm{IQR}=6$ years). The minimum (youngest) age of vaccination was one year versus the oldest maximum age of 13 years was answered (Table 4). However these findings did not show a statistically significant difference between normal vaccination ages for LTBI development $\left(\mathrm{KW} \chi^{2}(4)=3.330, p=0.504\right)$ (Figure 1).

Presence of BCG vaccination scar was not a statistically significant risk factor for LTBI development or to cause positive a TST reaction, even in those expatriates classified as 'high' and 'extremely high' LTBI cases who were having forearm scar.

A positive scar was detected in $86.11 \%(155 / 180)$ of participants $(\operatorname{LLR} \chi 2(4)=6.104, p=0.192)$. The overall median age of BCG vaccination for the participants was 5 years (IQR=2 years) (Table 4 ).

Immigrants having a history of exposure to poultry animals e.g. 


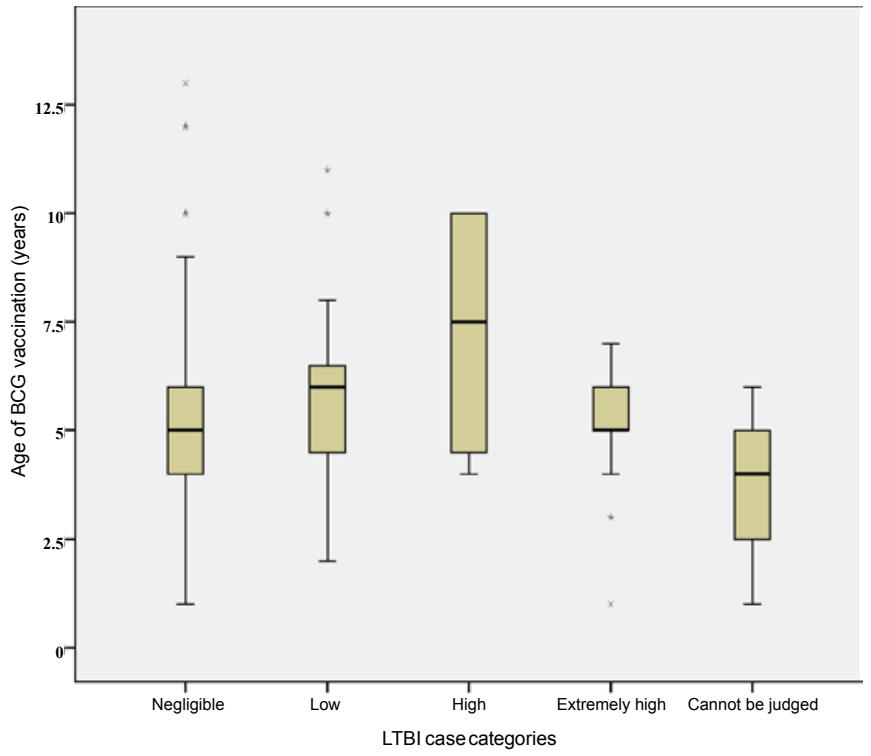

Figure1: Box-and-whisker plots of distribution of BCG vaccination age (years) according to the defined case categories of latent tuberculosis infection for 180 new immigrants to Kuwait during February and May, 2010 *Outlier values, xMaximum and minimum outlier values.

hen, duck and/or dairy animals e.g. goat, buffalo and/or dog in their mother country were $52.22 \%$ (94/180), and had no significant statistical association with LTBI suspicion except at the $10 \%$ level of significance according to the LTBI categories. Table 4 shows the distribution of the majority for those considered as 'negligible' LTBI cases in $56.67 \%$ (51/90) and 'extremely high' LTBI individuals in 52.17\% (24/46) (LLR $\chi 2(4)=7.928, p=0.094)$. On the other hand, a correlation between owning and/or exposure to cattle (cow) in mother countries and LTBI development was detected only in $15.56 \%(28 / 180)$ of total immigrant cases, but was not statistically significant $(\operatorname{LLR} \chi 2(4)=3.114, p=0.539)$ (Table 4).

\section{Discussion}

The influx of BCG-vaccinated immigrants in non-endemic countries from TB high-incidence regions represents a potential pool for new TB infection and highlights the need for LTBI early and accurate detection (reducing TB reservoirs) by using other higher specific diagnostics such as interferon gamma release assays (IGRAs) [10]. A common confounder, which affects TST reactivity, is prior vaccination with BCG vaccine, and/or the strain and dose of BCG used, and/or method of vaccine administration and age at vaccination. Successful vaccination can be assessed by the presence or absence of a BCG scar [11]. Similar finding was emphasized on skin testing in BCG-vaccinated populations to predict LTBI suspicious carriers [12]. Therefore TB skins testing at immigrant entry centres in Kuwait that serve large foreign-born populations can be effective and might add suspicion for LTBI carriers. Li et al. (2010) [13] detected LTBI prevalence of positive TST in $24.4 \%$ (higher among foreigners) in BCG-vaccinated which help to target TST testing before starting immigrant's chemoprophylaxis.

Exposure to previous BCG vaccination did not significantly reduce the risk of being diagnosed as active or latent TB was also revealed by Caley et al. (2010) [14], in common with our findings.

This study proved that the presence of a BCG scar and related TST negative results of all immigrants were not significantly associated with a higher prevalence of LTBI as also noted by Demkow et al. (2008) [15]. Other similar significant findings was detected the absence of risk difference in $\mathrm{TB}$ patient contacts having positive BCG scar compared to other normal control contacts without scars [16]. Also Kik et al. (2009) [17] showed no association between the presence of BCG scar with recent exposure to TB in immigrants having positive IGRAs and TST results.

Since BCG-TST positive reactivity wanes with time (if more than five years have elapsed since administration of BCG vaccine) - a positive TST reaction is most likely a result of exposure to MTB infection [18]. Gomes and colleagues (2011) [19] have recently concluded that waning of the BCG-induced protection was associated with raised risks of TB morbid rates in children aged between three and five years. Soysal et al. concluded that absence of an immunization scar can determine the likelihood for TB infection and is significantly associated with TB disease severity, which can be related to the level of exposure to MTB [2].

TST reactions can be interpreted regardless of BCG vaccination history [6]. Absence of positive TST reactions in our study strengthens the inference that BCG is not interfering with TST interpretation even though $86.11 \%(155 / 180)$ of participants had already been vaccinated against TB with BCG around pre-school ages. Similar related finding we rerecorded by Minodier et al. (2010) [20], namely that a positive TST is more likely to be related to an increased duration of TB exposure in the TB-endemic country of birth rather than to previous BCG vaccination. TST cannot be positive in certain biological factors due to suppression of DTH-IV reaction and T-lymphocytes such as malignancies and viral infections (e.g. HIV) [21].

Bradshaw et al. (2011) [22] suggested that advancing age increases the likelihood of exposure to unpasteurized dairy products and crossreactions of environmental mycobacterial antigens using IGRA tests. A similar significance in our research results of those participants having past history of exposures to various animals and positive BCG scar without LTBI diagnosis. On the contrary Grafein et al. (2011) [23] concluded that there was an absence of a significant association between the presence of LTBI and a BCG scar, but presence of a significant association with consumption of unpasteurized (cows) milk in the past 6 months, which can be related to Mycobacterium bovis.

Similar to the majority of BCG-related publications, the size of BCG scar was not measured in our research because did not correlate with protection against $\mathrm{TB}$, and also is not an indication for diagnosis (or presence) of LTBI. A similar result was also achieved by Crampin et al. (2009) [24].

TST reactivity caused by BCG vaccine generally wanes with the passage of time, but periodic skin testing may prolong reactivity in vaccinated persons, the phenomenon of 'boosting reactivity' [6] (CDC, 2010). On the contrary, TST reaction size and TST results were not affected by the time since the last dose of BCG vaccination, the number of BCG scars or BCG vaccination schedule in children, and significantly affected the decision for LTBI prophylaxis [25].

\section{Study Limitation and Strength}

The absence of a gold standard test for latent TB infection and TB can be considered as a limiting factor. Another limitation is the small sample size which might constrain generalization of the results to a larger population and wider community. On the other hand presenting and comparatively testing the new evidence-based diagnostic criteria for LTBI in addition to absence of any previous data on LTBI prevalence in immigrants or Kuwait residents add strength for future comparison. 
Citation: Harbie AA, Picozzi K, Thrusfield M, Sadek A, Welburn SC (2012) Is Bacille Calmette-Guérin (BCG) Vaccine a Known Risk Factor for Latent Tuberculosis Infection?: A Cross-sectional Study on 180 New Immigrants from BCG-vaccinated Countries to Kuwait. J Vaccines Vaccin 3:150. doi:10.4172/2157-7560.1000151

\section{Conclusions}

Tuberculin skin test is extremely limited as a diagnostic tool for latent tuberculosis infection to prove whether a positive result is caused by cross-reactivity resulting from BCG vaccination. Still a history of BCG and/or presence of vaccination scar (those answered 'No' or 'Unknown' vaccination status) is not a contraindication for tuberculin skin testing or LTBI chemoprophylaxis in suspected individuals.

\section{Recommendations}

The relationship between immunogenicity against tuberculin skin test in the response to $B C G$ vaccination needs to be elucidated. Considering the confounding effect of Mycobacterium tuberculosis risk factors, BCG efficacy and protection need further evaluation using interferon gamma release assays to compare between LTBI detected in both vaccinated and non-vaccinated populations. Emphasis on skin testing in BCG-vaccinated populations should be considered in the appropriate clinical setting to predict LTBI suspicious carriers.

\section{References}

1. Lalvani A, Sridhar S (2010) BCG vaccination: 90 years on and still so much to learn. Thorax 65: 1036-1038.

2. Soysal A, Millington KA, Bakir M, Dosanjh D, Aslan Y, et al. (2005) Effect of $B C G$ vaccination on risk of Mycobacterium tuberculosis infection in children with household tuberculosis contact: a prospective community-based study. Lancet 366: 1443-1451.

3. Ladefoged K, Rendal T, Skifte T, Andersson M, Søborg B, et al. (2011) Risk factors for tuberculosis in Greenland: case-control study. Int J Tuberc Lung Dis 15: $44-49$

4. CDC (2011) Tuberculin skin testing: Fact sheets. Centers for Disease Control and Prevention.

5. Richeldi $L$ (2006) An update on the diagnosis of tuberculosis infection. American Journal of Respiratory and Critical Care Medicine 174: 736-742.

6. CDC (2010) Latent Tuberculosis Infection: A Guide for Primary Health Care Providers. Division of Tuberculosis Elimination, Atlanta, Georgia. Centers for Disease Control and Prevention.

7. CIA (2000) Statistics with Confidence (Confidence Interval Analysis (CIA) Software). BMJ Books London 2000 ISBN: 0727913751.

8. SPSS 17.0 (Statistical Package for the Social Sciences-version 17.0.1), 2008 SPSS Statistics Base 17.0 User's Guide.

9. Thrusfield M (2007) Veterinary Epidemiology, Revised (3rded), Blackwell Science: Oxford

10. Pai M, Menzies D (2007) Interferon-gamma release assays: what is their role in the diagnosis of active tuberculosis?. Clin Infect Dis 44: 74-77.
11. Djuardi $Y$, Sartono $E$, Wibowo $H$, Supali $T$, Yazdanbakhsh $M$ (2010) A Longitudinal study of BCG vaccination in early childhood: the development of innate and adaptive immune responses. PLoS One 5: e14066.

12. Wang L, Turner MO, Elwood RK, Schulzer M, FitzGerald JM (2002) A metaanalysis of the effect of Bacille Calmette Guerin vaccination on tuberculin skin test measurements. Thorax 57: 804-809.

13. Li J, Munsiff SS, Agerton TB (2010) Prevalence of tuberculin skin test positivity in clinical population in New York City. J Immigr Minor Health 12: 816-822.

14. Caley M, Fowler T, Welch S, Wood A (2010) Risk of developing tuberculosis from a school contact: retrospective cohort study, United Kingdom, 2009. Euro Surveill 15: 19510

15. Demkow U, Broniarek-Samson B, Filewska M, Lewandowska K, Maciejewski J, et al. (2008) Prevalence of latent tuberculosis infection in health care workers in Poland assessed by interferon-gamma whole blood and tuberculin skin tests. $J$ Physiol Pharmacol 6: 209-217.

16. Lin X, Chongsuvivatwong V, Lin L, Geater A, Lijuan R (2008) Dose-response relationship between treatment delay of smear-positive tuberculosis patients and intra-household transmission: a cross-sectional study. Trans R Soc Trop Med Hyg 102: 797-804

17. Kik SV, Franken WP, Arend SM, Mensen M, Cobelens FG (2009) Interferongamma release assays in immigrant contacts and effect of remote exposure to Mycobacterium tuberculosis. Int J Tuberc Lung Dis 13: 820-828.

18. CDC (2005) TB Elimination: Targeted Tuberculin Testing and Interpreting Tuberculin Skin Test Results. Centers for Disease Control and Prevention.

19. Gomes VF, Andersen A, Wejse C, Oliveira I, Vieira FJ, et al. (2011) Impact of tuberculosis exposure at home on mortality in children under 5 years of age in Guinea-Bissau. Thorax 66: 163-167.

20. Minodier P, Lamarre V, Carle ME, Blais D, Ovetchkine P, et al. (2010) Evaluation of a school-based program for diagnosis and treatment of latent tuberculosis infection in immigrant children. J Infect Public Health 3: 67-75.

21. LoBue PA, Enarson DA, Thoen CO (2010) Tuberculosis in humans and animals: an overview. Int J Tuberc Lung Dis 14: 1075-1078.

22. Bradshaw L, Davies E, Devine M, Flanagan P, Kelly P, et al. (2011) The role of the interferon gamma release assay in assessing recent tuberculosis transmission in a hospital incident. PLoS ONE 6: e20770.

23. Garfein RS, Burgos JL, Rodriquez-Lainz A, Brodine S, Pietrucha A, et al (2011) Latent tuberculosis infection in a migrant agricultural community in Baja California, Mexico. J Immigr Minor Health 13: 940-947.

24. Crampin AC, Glynn JR, Fine PE (2009) What has Karonga taught us? Tuberculosis studied over three decades. Int J Tuberc Lung Dis 13: 153-164.

25. Hocaoğlu AB, Erge DO, Anal O, Makay B, Uzuner N, et al. (2011) Characteristics of children with positive tuberculin skin test. Tuberk Toraks 59: 158-163. 